dự phòng, Tập 29 (số 5), trg: 107.

4. Nguyễn Nhật Cảm, Phí Thị Hương Liên (2017) "Thức trang tiêm chủng đầy đủ đúng lich 8 loai vắc xin ở trẻ em dưới 1 tuổi và yếu tố liên quan tại khu vực thành thị thành phố Hà Nội, năm 2016". Tạp chí y học dự phòng, Tập 27 ( số 6), trg: 118.

5. Đổ Thị Thắm (2018) "Thực trang tiêm chủng đây đủ, đủng lich và một số yếu tố ảnh hưởng ở tré dưới 1 tuổi tại huyện Trạm Tấu, Mù Cang Chải, tỉnh Yên Bái năm 2017". Tap chí y hoc dư phòng, diên đàn khoa học của hội y học dự phòng, 28 (4), 9.

6. Hoàng Anh Thẳng (2020) "Tỷ lệ tiêm chủng đây đủ, đúng lịch của tré em giai đoạn 5 năm (2015-
2019) và một số yếu tố liên quan đến tỷ lệ tiêm chủng đầy đủ, đúng lịch tại Thành Phố Vũng Tàu, tỉnh Bà Ria Vũng Tàu". Khóa luân tốt nghiêp Thac sỹ Y học dự Phòng 2020 - Đại học Y Dược tp Hồ Chí Minh,

7. UNICEP Chương trình Tiêm chủng https://www.unicef.org/vietnam/vi/ti\%C3\%AAmch\%E1\%BB\%A7ng,

8. Lý Thị Thúy Vân, Đỗ Thi Thanh Toàn, Dương Thị Hồng, Nguyễn Công Luật, Nguyê̂n Bá Đoàn, Nguyến Mai Khanh, et ăl. (2020) "Thức trạng tiêm chủng đây đủ đúng lịch cho trẻ dưới 1 tuổi tại huyênn Bình Liễu, tỉnh Quảng Ninh năm 2020". Tạp chí Y học Dự phòng, 30 (7), 35.

\title{
KẾT QUẢ ĐIỀU TRI HÓA XẠ TRI UNG THƯ TRỰC TRÀNG GIAI ĐOÂN III TRƯớC MỔ
}

\author{
Hoàng Văn An*, Hoàng Mạnh An*, Nguyễn Anh Tuấn**
}

TÓM TẮT

Mục tiêu: Đánh giá kết quả điều trị hóa xạ trị ung thư trực tràng giai đoạn III với Cappecitabine trước mổtại Bệnh viện Trung ương quân đội 108. Đối tượng và phường pháp: Nghiên cứu mồ tả tiến cứu và hồi cứu từ tháng 12.2015 đến tháng 3.2020 trên 73 bệnh nhân ung thư trực tràng giai đoạn IIIcòn khả năng phẫu thuật, được hóa xạ tiền phẫu liều $50,4 \mathrm{~Gy} / 28 \mathrm{fx}$ trong 5,5 tuần cùng với Capecitabine $825 \mathrm{mg} / \mathrm{m} 2$, 2 lần/ngày, x 5-7 ngày/tuần. Các bệnh nhân được tiến hành phẫu thuật sau 4-12 tuần kết thúc hóa xạ trị. Đánh giá độc tính do hóa xạ trị, đáp ứng trên lâm sàng, đáp ứng trên giải phẫu bênh sau mổ, khả năng bảo tồn cơ thắt hậu môn và biến chứng sau mổ. Kết quả: Tỷ lệ đáp ứng toàn bộ trên lâm sàng là $75,3 \%(55 / 73)$, trong đó có $8,2 \%(6 / 73)$ đáp ứng hoàn toàn. Trên giải phẫu bệnh sau mổ, tỷ lệ bệnh nhân đáp ứng làm giảm giai đoạn khối u $(\mathrm{T})$ là $54,79 \%$ (40/73), trong đó 4,1\% (3/73) đạt đáp ứng hoàn toàn (pTO). Tất cả bệnh nhân dung nạp điêuu trị tốt, không có độc tính độ 4, thường gặp viêm trực tràng do xạ trị độ $1-2$ chiếm $27,4 \%$ (20/73) và độ 3 có 01 trường hợp chiếm $1,3 \%$, viêm da do xa trị đồ $1-2$ có30,1\% (22/73), mệt mỏi độ $1-2$ có $17,8 \%$ (13/73), viêm đường tiết niệu đô 1 có $8,2 \%(6 / 73)$, sút cân $9,6 \%$ (7/73). Phẫu thuật bảo tồn cơ thắt đạt $84,9 \%$ (62/73). Biến chứng sau mổ chỉ có $6,8 \%(5 / 73)$ rò miệng nối. Kết luận: Điều trị hóa xa trị ung thư trực tràng giai đoạn III với Capecitabine đạt tỷ lệ cao giảm giai đoạn sau điều trị, làm tăng khả năng phẫu thuật bảo tồn cơ thắt.

Tư khóa: Hóa xạ tiền phẫu, ung thư trực tràng.

*Bệnh viện Quân y 103

**Bênh viên TƯQQ 108

Chịu trách nhiệm chính: Hoàng Văn An

Email: hoangnguyenantam@gmail.com

Ngày nhận bài: 17/10/2021

Ngày phản biên khoa hoc: 19/11/2021

Ngày duyệt bài: 12/12/2021

\section{SUMMARY \\ THE RESULTS OF PREOPERATIVE CHEMO- RADIOTHERAPY TREATMENT FOR STAGE III RECTAL CANCER}

Objectives: To evaluate the results of surgery treatment for stage III rectal cancer with preoperative chemo-radiotherapy with Cappecitabine at Central Military Hospital 108. Subjects and methods: Progressive and retrospective descriptive research on 73 patients with rectal cancer Stage III from December 2015 to March 2019 who have received preoperative chemoradiotherapy with $50.4 \mathrm{~Gy} / \mathrm{Fx}$ dose in 5.5 weeks with Capecitabine $825 \mathrm{mg} / \mathrm{m2}$, twice a day $x$ 5-7 days/week and surgery. All of the patients underwent surgery after 4 to 12 weeks since finishing chemoradiotherapy. Evaluate the toxicity of chemoradiotherapy, clinical response, postoperative pathological anatomy response, sphincter preservation and postoperative complications. Results: Rate of clinical complete response is $75,3 \%(55 / 73)$, including $8.2 \%(6 / 73)$ of comprehensive response. In terms of postoperative anatomy, rate of patients with tumor $(T)$ period reduction response is $54.79 \%$ (40/73), including $4.1 \%(3 / 73)$ of comprehensive response (pT0). All patients tolerated treatment well, no toxicity at level 4 . Rectal inflammation caused by radiation at level 1-2 accounts for $27.4 \%(20 / 73)$ and at level 3 accounts for $1.3 \%$ with 1 case, dermatitis due to radiation at level $1-2$ accounts for $30.1 \%(22 / 73)$, fatigue at level $1-2$ accounts for $17.8 \%$ (13/73), urinary tract inflammation at level 1 accounts for $8.2 \%$ (6/73), weight loss accounts for $9.6 \%$ (7/73). Anal sphincter conservation surgery reaches $84.9 \%$ (62/73). Postoperative complications account for only $6.8 \%(5 / 73)$ of leakage. Conclusion: Stage III rectal cancer treatment results by preoperative chemoradiotherapy with Capecitabine have achieved high rate of post-operative period reduction and increase the capability of anal sphincter conservation surgery.

Key words: Preoperative chemo-radiotherapy, rectal cancer. 


\section{I. ĐẶT VẤN ĐỀ}

Ung thư trực tràng (UTTT) là một trong những bệnh ung thư phổ biến ở nước ta và các nước trên thế giới. Tỳ lệ mắc UTTT trên thế giới ngày càng tăng. Tỷ lệ mắc và tỷ lệ tử vong của UTTT thay đổi rõ rệt trên toàn thế giới. Trên toàn cầu, UTTT là bệnh ung thư được chẩn đoán phổ biến thứ ba ở nam và thứ hai ở nữ, với 1,8 triệu trường hợp mới và gần 861.000 ca tử vong trong năm 2018 theo cơ sở dữ liệu GLOBOCAN của Tổ chức $Y$ tế Thế giới. Tỷ lể này cao hơn đáng kể ở nam so với nữ. Tại Việt Nam, tỷ lệ mắc ung thư đại trực tràng cao thứ 5 trong các bệnh ung thư, sau ung thư phổi, ung thư dạ dày, ung thư vú và ung thư vòm họng. Tỷ lệ tử vong đứng thứ 4 sau ung thư gan, ung thư phổi, ung thư da dày.

Xu hướng điều tri ung thư trực tràng hiên nay là phối hợp đa mô thức, bao gồm nhiều phương pháp điều trị như phẫu thuật, hóa chất, tia xạ, điều trị đích, điều trị điều hòa miễn dịch...Việ̣c lựa chọn phác đồ điều trị thích hợp phụ thuộc vào nhiêu yếu tố: toàn trạng bệnh nhân, vị trí u nguyên phát, giai đoạn bệnh và các yếu tố nguy cơ.

Phẫu thuật là phương pháp điêu trị triệt căn đối với ung thư trực tràng. Tuy nhiên, các bệnh nhân chỉ phẫu thuật đơn thuần có tỷ lệ thất bại tại vùng cao (25-50\%) [2]. Xạ trị có vai trò quan trọng trong kiểm soát tái phát tại vùng; tỷ lệ tái phát tại vùng sau 5 năm ở nhóm xạ trị sau phẫu thuật thấp hơn nhóm chỉ phẫu thuật tương ứng là $15 \%$ và $23 \%$ [1]. Hóa chất là phương pháp điều trị toàn thân, giúp kiểm soát di căn xa và vi di căn. Hóa chất khi kết hợp xạ trị giúp tăng nhạy cảm tế bào u với tia xạ. Đã có những nghiên cứu chứng minh lợi ích và sự an toàn của xạ trị tiền phẫu ngắn ngày, làm tăng tỷ lệ kiểm soát vùng và thời gian sống thêm [3]. Tuy nhiên, hóa xạ tiền phẫu dài ngày còn có thể làm giảm kích thước u và giai đoạn bệnh sau điều trị, qua đó tăng tỷ lệ phẩu thuật bảo tồn cơ thắt, nâng cao chất lượng sống cho bệnh nhân [4].

Theo hướng dẫn thực hành của mạng lưới ung thư toàn diện Mỹ, có ba phác đồ hóa chất khi kết hợp xạ trị trong điều trị ung thư trực tràng tiền phấu thuật, gồm: 5-FU truyền liên tục, Capecitabine uống (khuyến cáo mức 1) và 5FU/Leucovorin truyền (khuyến cáo mức $2 \mathrm{~A}$ ). Capecitabine là một dẫn xuất của fluoropyrimidine carbamate, nó được chuyển hóa thành 5-FU ưu thế và chọn lọc trong mô khối u, dó đó hạn chế tác dụng độc tính trên các tế bào lành. Hớn nữa, Capecitabine dùng đường uống nên rất tiện lợi khi sử dụng, bệnh nhân không phải nằm viện mà tránh được các tác dụng phụ trên mạch máu do đường truyền hóa chất gây ra. Như vậy, hóa xạ trị đồng thời với Capecitabine là rất thuận lợi cho điều trị tiền phẫu bệnh nhân ung thư trực tràng [5]. Tại Bệnh viện Trung ương quân đội 108 , chúng tôi đã áp dụng phác đồ hóa xạ tiền phẫu với Capecitabine cho những bệnh nhân ung thư trực tràng giai đoạn IIIcòn khả năng phẫu thuật từ năm 2015, bước đầu có kết quả khả quan. Vì vậy, chúng tôi tiến hành nghiên cứu với mục tiêu: Đánh giá kết quảbước đầu điều trị hóa xạ trị ung thu trực tràng giai đoạn IIIvới Capecitabine trước mô.

\section{II. ĐỐI TƯợNG VÀ PHƯƠNG PHÁP NGHIÊN CỨU}

Nghiên cứu mô tả tiến cứu và hồi cứu trên 73 bệnh nhân ung thư trực tràng giai đoạn III còn khả năng phẫu thuật từ 12. 2015 đến 3.2020 tại Bệnh viện Trung ương quân đội 108.

\section{* Tiêu chuẩn lứa chon bênh nhân:}

- Bệnh nhân được chẩn đoán là ung thư biểu mô tuyến trực tràng giai đoạn III.

- Bệnh nhân được chỉ định hóa xạ trị trước mổ kết hợp phẫu thuật cắt bỏ trực tràng ngay sau hóa xạ trị, có hoặc không bảo tồn cơ thắt.

- Điểm toàn trang ECOG 0-2 điểm.

- Bệnh nhân không có chống chỉ định hóa xạ trị: Chức năng tuỷ xương, gan, thận trong giới hạn bình thường.

- Đồng ý tham gia vào nghiên cứu.

* Tiêu chuấn loại trừ: -Bệnh nhân được chẩn đoán Giải phẫu bệnh lý sau mổ không phải là ung thư biểu mô tuyến trực tràng.

- Bệnh nhân UTTT giai đoạn III đã có biến chứng: Tắc ruột, chảy máu cấp tính, thủng...phải mổ cấp cứu cắt trực tràng.

-Điểm toàn trạng ECOG >2 điểm.

- Bệnh nhân có chống chỉ định với hóa xạ trị theo tiều chuẩn: Bệnh lý nặng kết hợp, không có khả năng phối hợp hóa xa trị và phẫu thuật, thiếu máu, bạch cầu và tiểu cầu giảm mức độ nặng, phụ nữ mang thai.

- Bệnh nhân không thực hiện được đầy đủ qui trình hóa xạ trị, phẫu thuật và theo dõ̃i sau mổ.

- Ung thư ống hậu môn.

- Không đồng ý tham gia vào nghiên cứu.

\section{* Quy trinh điều trị:}

- Đánh giá trước điêu tri: Các BN được làm chẩn đoán giai đoạn ban đầu bằng nội soi đại trực tràng sinh thiết, chụp $\mathrm{CT} / \mathrm{MRI}$ bụng chậu, Xquang phổi, XN máu, CEA. Chẩn đoán giai đoạn bệnh dựa vào phân loại giai đoạn năm 2010 của hội ung thư Mỹ. Hội chẩn điều trị thông qua hội 
đồng ung thư.

- Xa trị: Xạ trị tiền phẫu với cách phân liều 45Gy/25 fx cho phần sau của khung chậu bao gồm: khối u, cân quanh trực tràng, hạch chậu trong hai bên, hạch trước xương cùng, và hạch bịt hai bên. Nếu tổn thương xâm lấn ra các tạng phía trước như bàng quang, tử cung, tiền liệt tuyến thì bao gồm cả hạch chậu ngoài hai bên. Sau đó, nâng liêu tại u (mở rộng biên $2 \mathrm{~cm}$ quanh u) và cân trực tràng tương ứng, đạt tổng liêu $50,4 G y$. Phân liều quy ước: $1,8 \mathrm{G} y / n g a ̀ y, ~ 5$ ngày/tuần x 5,5 tuần.

- Hóa chất: Capecitabine $825 \mathrm{mg} / \mathrm{m} 2,2$ lần/ngày, x 5-7 ngày/tuần x 5 tuần xạ.

- Phấu thuật: được tiến hành sau 4-12 tuần kết thúc hóa xa tri.

- Đánh giá độc tính và đáp ứng điều trị: đánh giá độc tính hóa - xạ hàng tuần theo tiêu chuẩn của Viện ung thư quốc gia Mỹ CTCAE 4.0. Đánh giá đáp ứng điều trị sau hóa xạ 1 tháng (hoặc trước phẫu thuật) và sau phẫu thuật bằng CT/MRI khung chậu và nội soi. Đánh giá đáp ứng cả trên lâm sàng và giải phẫu bệnh sau mổ.

* Xử lý số liệu: bằng phần mềm SPSS 20.0.

\section{KẾT QUẢ NGHIÊN CỨU VÀ BÀN LUÂ̂N}

- Về đặc điểm bệnh nhân (Bảng 1): Từ 12.2015 đến 3.2020 chúng tôi đưa vào nghiên cứu 73 bệnh nhân ung thư trực tràng giai đoạn III còn khả năng phẩu thuật. Nghiên cứu bao gồm 42 nam và 31 nữ, với độ tuổi trung bình là $62,9 \pm 11,0$ (36-81) tuổi. Các bệnh nhân nhập viện với triệu chứng thường gặp nhất là đại tiện phân nhây máu $(95,9 \%)$, sau đó là đau tức hạ vị (52\%), mót rặn (63\%), phân táo lỏng $(42,4 \%)$. Kết quả sinh thiết nội soi đa phần là ung thư biểu mô tuyến biệt hóa vừa $(84,9 \%)$, biệt hóa tốt: 8,2\%, biệt hóa kém: 05 trường hợp (6,9\%).

- Về vị trí giải phẫu, tỷ lệ ung thư trực tràng đoạn $1 / 3$ trên, giữa, dưới lần lượt là $11 \%, 32,9 \%$ và $56,1 \%$. Bệnh nhân hoàn thành được quy trình điều trị hóa xạ tiền phẫu cũng như phẫu thuật, đều được đánh giá đáp ứng điều trị trên lầm sàng, giải phẫu bệnh và các độc tính.

\section{Bảng 1. Đăc điểm chung}

\begin{tabular}{|l|c|c|}
\hline \multicolumn{2}{|c|}{ Tuối } & \multicolumn{2}{|c|}{$62,9 \pm 11,0$} & $(36-81)$ \\
\hline \multirow{2}{*}{ Giới } & $\mathbf{n}$ & $\mathbf{\%}$ \\
\cline { 2 - 3 } & 42 & 57,5 \\
Naú & 31 & 42,5 \\
\hline Triệu chứng & & \\
Phân nhầy máu & 70 & 95,9 \\
Đau bưng hạ vị & 38 & 52 \\
Mót rặn & 46 & 63 \\
Phân táo -lỏng & 31 & 42,4 \\
\hline
\end{tabular}

\begin{tabular}{|c|c|c|}
\hline $\begin{array}{ll}\text { ECOG: } & 0 \\
& 1 \\
& 2 \\
\end{array}$ & $\begin{array}{c}14 \\
58 \\
1\end{array}$ & $\begin{array}{c}19,2 \\
79,5 \\
1,4 \\
\end{array}$ \\
\hline $\begin{array}{c}\text { Giải phâu bệnh } \\
\text { Biệt hóa tốt } \\
\text { Biệt hóa vứa } \\
\text { Biệt hóa kém }\end{array}$ & $\begin{array}{c}6 \\
62 \\
5\end{array}$ & $\begin{array}{c}8,2 \\
84,9 \\
6,9\end{array}$ \\
\hline $\begin{array}{ll}\text { Vị trí u: } & 1 / 3 \text { Trên } \\
& 1 / 3 \text { Giữa } \\
& 1 / 3 \text { Dưới }\end{array}$ & $\begin{array}{c}8 \\
24 \\
41\end{array}$ & $\begin{array}{c}11 \\
32,9 \\
56,1\end{array}$ \\
\hline
\end{tabular}

- Về độc tính do hóa xạ đồng thời (Bảng 2): Tất cả các bệnh nhân dung nạp điều trị tốt, cũng không có bệnh nhân nào tử vong liên quan đến điều trị. Các độc tính thường gặp là viêm trực tràng do xạ trị độ 1 chiếm 24,6\% (18 bệnh nhẩn độ 1$)$, độ 2 có 02 trường hợp chiếm $2,7 \%$ và độ 3 gặp ở 01 bệnh nhân $(1,3 \%)$. Viêm da độ 1 có $14(19,2 \%)$, độ 2: $8(10,9 \%)$ và không gặp viêm da độ 3-4. Ngoài ra, biểu hiện mệt mỏi độ 1 có $12(16,4 \%)$, độ 2 có $01(1,3 \%)$, viêm đường tiết niệu độ 1 có $06(8,2 \%)$, sút cân $(9,6 \%)$, buồn nôn 01 bệnh nhân $(1,3 \%)$, có 02 trường hợp hạ bạch cầu độ $1(2,7 \%)$. Hầu hết các độc tính xảy ra ở mức độ nhẹ, có thể tự hồi phục được.

Điêu này cho thây tính an toàn và phù hợp của phác đồ hóa xạ khi kết hợp với Capecitabine. Nghiên cứu GERCOR [6] cũng đã khẳng định phác đồ hóa xạ này cho độc tính thấp và an toàn.

Bảng 2. Độc tính do hóa xạ trị.

\begin{tabular}{|c|c|c|}
\hline \\
\hline $\begin{array}{l}\text { Bien chưng } \\
\text { Mêt mỏi đô 1 }\end{array}$ & $\frac{\mathrm{n}}{12}$ & $\%$ \\
\hline Buồn nôn đô 1 & $\begin{array}{c}12 \\
1\end{array}$ & $\begin{array}{c}10,4 \\
1,3\end{array}$ \\
\hline Viêm đường tiết niệu độ 1 & 6 & 8,2 \\
\hline Độ 1 & 14 & 19,2 \\
\hline Đố 2 & 8 & 10,9 \\
\hline Viêm trực tràng do xạ & & \\
\hline $\begin{array}{l}\text { Đo } 1 \\
\text { Đố } 2\end{array}$ & $\begin{array}{c}18 \\
2\end{array}$ & $\begin{array}{c}24,6 \\
2,7\end{array}$ \\
\hline Đổ 3 & 1 & 1,3 \\
\hline Sút cân khi xạ & 7 & 9,6 \\
\hline Ha BC do xạ độ 1 & 2 & 2,7 \\
\hline
\end{tabular}

- Đánh giá đáp ứng trên lâm sàng (Bảng 3):

Các bệnh nhân được đánh giá đáp ứng trên lâm sàng sau khi đã kết thúc hóa xạ trị và trước khi phẫu thuật. Dựa trên thăm khám lâm sàng, nội soi trực tràng, hình ảnh MRI/CT khung chậu, chúng tôi thấy có $55(75,3 \%)$ bệnh nhân đáp ứng trên lâm sàng, trong đó có $6(8,2 \%)$ đáp ứng hoàn toàn và $49(67,1 \%)$ đáp ứng 1 phần. Kết quả này tương tự như nhiều nghiên cứu khác đã công bố với tỷ lệ đáp ứng trên lâm sàng là 70$90 \%$ [7]. Trong nghiên cứu của chúng tôi có 1 bệnh nhân tiến triển $(1,3 \%)$, bệnh nhân di căn gan sau hóa xạ trị (giai đoạn III-> giai đoạn IV). 
Bảng 3. Đáp ứng điều trị .

\begin{tabular}{|c|c|c|}
\hline & $\mathbf{n}$ & $\mathbf{\%}$ \\
\hline Đáp ứng hoàn toàn & 6 & 8,2 \\
\hline Đáp ứng 1 phần & 49 & 67,1 \\
\hline Bệnh ồn định & 17 & 23,3 \\
\hline Bệnh tiến triển & 1 & 1,4 \\
\hline
\end{tabular}

- Về kết quả phấu thuật (Bảng 4):

Phẫu thuật cắt trước thấp (bảo tồn cơ thắt) có 61 bệnh nhân $(83,6 \%)$, phẫu thuật đường bụng tầng sinh môn (PT Miles) 12 bệnh nhân $(16,4 \%)$. Khi phân tích dưới nhóm U trực tràng $1 / 3$ dưới thì tỷ lệ phẫu thuật bảo tồn cơ thắt đạt $31 / 7342,5 \%$, tỷ lệ này cao hơn nghiên cứu của tác giả Phạm Cẩm Phương (12,6\%)[8]. Sauer và cs [4] cũng đã cho thấy hóa xạ tiên phẫu làm tăng khả năng bảo tồn cơ thắt ở những bệnh nhân có chỉ định phẫu thuật qua đường bụng tầng sinh môn (PT Miles). Chỉ có 5 bệnh nhân $(6,7 \%)$ rò miệng nối. Ngoài ra, không có biến chứng, tai biến nặng nề sau phẩu thuật cần can thiệp ngoại khoa lớn. Kết quả này tương tự với nghiên cứu của Kim JC.

Bảng 4. Tỷ lệ phẫu thuật và bảo tồn cơ thắt.

\begin{tabular}{|c|c|c|c|c|}
\hline \multirow{2}{*}{} & \multicolumn{2}{|c|}{$\begin{array}{c}\text { PT cắt trước } \\
\text { thấp (Bảo tôn } \\
\text { cơ thắt) }\end{array}$} & $\begin{array}{c}\text { PT qua đường } \\
\text { bunng tâng sinh } \\
\text { môn }\end{array}$ \\
\cline { 2 - 5 } & $\mathbf{n}$ & $\mathbf{\%}$ & $\mathbf{n}$ & $\mathbf{\%}$ \\
\hline U 1/3 trên & 8 & 10,9 & 0 & 0 \\
\hline U 1/3 giữa & 22 & 30,1 & 2 & 2,7 \\
\hline U 1/3 dưới & 31 & 42,4 & 10 & 13,7 \\
\hline Tống & 61 & 83,4 & 12 & 16,4 \\
\hline
\end{tabular}

- Về đáp ứng điều trị dựa trên kết quả giải phẫu bệnh sau mổ (Bảng 5,6): Khi so sánh giai đoạn khối u $(T)$ sau mố với thời điểm trước khi hóa xạ, chúng tôi thấy có 40 bệnh nhân $(54,79 \%)$ giảm giai đoạn $\mathrm{T}$, trong đó có 3 ca $(4,1 \%)$ đáp ứng hoàn toàn về mặt giải phẫu bệnh (pT0). Tương tự, đánh giá đáp ứng giải phẫu bệnh của hạch vùng $(\mathrm{N})$, nghiên cứu của chúng tôi có $71 \mathrm{ca}(97,26 \%)$ giảm giai đoạn hạch vùng. Có 2 bệnh nhân $(4,1 \%)$ đáp ứng hoàn toàn cả khối u và hạch vùng (pTONO), 18 bệnh nhân về giai đoạn I $(24,7 \%)$, 44 bệnh nhân về giai đoạn II $(60,3 \%)$. Các nghiên cứu trước đây cho tỷ lệ đáp ứng hoàn toàn khối u từ 4\%$31 \%[3],[4],[5],[6]$.

Bảng 5. Đáp ứng điều trị của mức độ xâm lấn trên giải phẫu bệnh sau mổ

\begin{tabular}{|c|c|c|c|c|c|c|}
\hline $\begin{array}{c}\text { Mức độ xâm lấn (T) trên GPB } \\
\text { Mức độ xâm } \\
\text { lấn(T) trước HXT }\end{array}$ & pT0 & pT1 & pT2 & pT3 & pT4 & $\begin{array}{c}\text { Giảm mức độ } \\
\text { xâm lấn (T) sauu } \\
\text { HXT }\end{array}$ \\
\hline CT3 & 2 & 1 & 15 & 26 & 3 & $18 / 47(38,29 \%)$ \\
\hline CT4 & 1 & 2 & 3 & 16 & 4 & $22 / 26(84,61 \%)$ \\
\hline Tổng & 3 & 3 & 18 & 42 & 7 & $40 / 73(54,79 \%)$ \\
\hline
\end{tabular}

Bảng 6. Đáp ứng điều trị của hạch vùng trên giải phẩu bệnh sau mổ.

\begin{tabular}{|c|c|c|c|}
$\begin{array}{l}\text { Hạch ở GPB } \\
\text { Hach trước } \\
\text { HX̃T }\end{array}$ & pNo & pN1 & $\begin{array}{c}\text { Giảm số lương } \\
\text { hạch sau HXT }\end{array}$ \\
\hline CN1 & 26 & 2 & $26 / 28(92,85 \%)$ \\
\hline CN2 & 38 & 7 & $45 / 45(100 \%)$ \\
\hline Tống & 64 & 9 & $71 / 73(97,26 \%)$ \\
\hline
\end{tabular}

\section{KẾT LUẬN}

Hóa xạ trị tiền phẫu với Capecitabine ở bệnh nhân ung thư trực tràng giai đoạn III còn khả năng phẩu thuật là phương pháp điều trị an toàn, hiệu quả, ít độc tính, đạt được tỷ lệ giảm giai đoạn sau phẫu thuật khá cao, làm tăng khả năng phẫu thuật bảo tồn cơ thắt.

\section{TÀI LIẸU THAM KHẢO}

1. Global Burden of Disease Cancer Collaboration, Fitzmaurice C., Allen C., et al (2017), "A Systematic Analysis for the Global Burden of Disease Study", JAMA Oncol, 3:pp.524.

2. O'Connell M.J. et al (2005), "Update on design of the National Surgical Adjuvant Breast and Bowel
Project trial R-04", J Clin Oncol, 23:pp.933-934.

3. Camma C., Giunta M., Fiorica Fet al (2000), "Preoperative radiotherapy for resectable rectal cancer: A meta-analysis", JAMA, 284:pp.1008-1015.

4. Sauer R., Becker H., Hohenberger Wet al (2004), "Preoperative versus postoperative chemoradiotherapy for rectal cancer", N Engl J Med, 351:pp.1731-1740.

5. Twelves C. (2002), "Xeloda Colorectal Cancer Group. Capecitabine as first-line treatment in colorectal cancer: Pooled data from two large, phase III trials", Eur J Cancer, 38(2):pp.15-20.

6. Dupuis O., Vie B., Lledo Get al (2004), "Capecitabine chemoradiation in the preoperative treatment of patients with rectal adenocarcinomas: a phase II GERCOR trial", Proc Am Soc Clin Oncol, 23:pp. 255.

7. Gambacorta M.A., Valentini V., Morganti A.G. et al (2004), "Chemoradiation with raltitrexed and oxaliplatin in preoperative treatment of stage II-III resectable rectal cancer: Phase I and II studies", Int J Radiat Oncol Biol Phys, 60:pp.139-148.

8. Phạm Cẩm Phương (2013), "Đánh giá hiệu quả của xạ trị kết hợp Capecitabine trước mổ trong ung thư trực tràng thấp tiến triển tại chố". Luận án tiến sỹ Y kh̉oa, Đại học Y Hà Nội. 